\title{
The Effects of Caring for Young Children with Developmental Disabilities on Mothers' Health and Healthcare Use: Analysis of Primary Care Data in the Born in Bradford Cohort
}

\author{
Sarah C. Masefield ${ }^{1,2}$ - Stephanie L. Prady ${ }^{1}$ (D) Trevor A. Sheldon ${ }^{3}$. \\ Neil Small $^{4}$ (D) Stuart Jarvis ${ }^{1}$ (D) Kate E. Pickett $^{1}$ (D)
}

Accepted: 3 February 2021 / Published online: 8 April 2021

(c) The Author(s) 2021

\begin{abstract}
We explored the association between caregiving for preschool children with developmental disabilities and maternal health and healthcare use using linked primary care and Born in Bradford birth cohort data. Adjusting for prenatal health, healthcare use and socioeconomic status, mothers who were caregivers were more likely than other mothers to have symptoms of psychological distress (odds ratio 1.24; $95 \%$ CI 1.01, 1.53), exhaustion $(1.42 ; 1.12,1.80)$ and possibly head and musculoskeletal pain $(1.18 ; 0.97,1.43)$. Despite the higher prevalence of symptoms, they did not access healthcare services more and may seek healthcare for psychological distress less often $(0.64 ; 0.40,1.02)$. In general, socioeconomic disadvantage was associated with worse health. Pakistani ethnicity (versus white British) and prenatal consultation were strongly associated with higher postnatal consultation rates. Prenatal ill health, healthcare use and socioeconomic status are important factors in the detection of postnatal ill health via primary care services. If caregiver burden and the risk of under-detecting (and thus under treating) caregiver ill health is not addressed during the preschool period health inequalities between caregivers and other mothers and their families may persist and grow. The health of mothers of young disabled children, in particular their unmet health needs, warrants attention in research and clinical practice.
\end{abstract}

Keywords Child disability $\cdot$ Developmental disabilities $\cdot$ Preschool $\cdot$ Maternal health $\cdot$ Healthcare use $\cdot$ Primary care

Sarah C. Masefield

sarah.masefield@york.ac.uk

Extended author information available on the last page of the article 


\section{Introduction}

Developmental disabilities are long term physiological impairments that significantly affect a child's ability to perform activities of daily living, such as independent feeding, mobility, and communication (Unicef and World Health Organization 2012). Globally, $8.4 \%$ of children younger than 5 years were estimated to have developmental disabilities in 2016 (Olusanya et al. 2018). The preschool period (child age 0-5 years) is when most parents will notice developmental differences between their child and other children. This is when they are most likely to seek and receive a specific disability diagnosis, such as Down syndrome, or a diagnosis of developmental delay or a developmental disorder, which are indicators of disability (Cans et al. 2008). During this period, families are adjusting to the diagnosis and its implications for their life. Caregivers describe this as a period of high emotional stress (Mayberry and Heflinger 2013).

Parents of children with disabilities experience ongoing psychological and physical demands and adverse economic impacts of the caregiving role (Masefield et al. 2020; Chambers and Chambers 2015). For example, primary caregivers (usually the mother) frequently cannot return to work (Working Families and Unum 2018). Family breakdown is more common and isolation from friends and family is frequently reported (Marquis et al. 2019), Accordingly, there is substantial evidence that caregivers are more likely than mothers of typically developing children to experience higher levels of stress, anxiety and depression (Marquis et al. 2019; Masefield et al. 2020), and a greater likelihood of a large range of physical conditions and symptoms (Lee et al. 2017; Miodrag et al. 2015). Stress (due to the additional burden of caregiving) is typically assumed as the causal mechanism in the relationship between caregiving and ill health (Raina et al. 2004). Here we use ill health to mean the signs, symptoms and conditions of poor health.

Despite the evidence of worse physical and mental health in caregivers, there may be barriers preventing caregivers from seeking timely healthcare for their own health problems (Willet et al. 2018), such as less time available due to caregiving tasks and diminished support networks to assist with childcare to attend appointments (Carlson and Miller 2017). However, no studies exploring this have been carried out in the United Kingdom (UK). Most of the research on caregiver health has focused exclusively on stress and depression and in caregivers of older child age groups (above five years) (Masefield et al. 2020).

Born in Bradford (BiB) is a large multi-ethnic birth cohort in a city in the north of England, UK. It has extensive sociodemographic data for the mothers and linkage to the mother and child primary care records $(n=12,453$ mothers, 13,776 pregnancies, 3448 fathers) (Wright et al. 2013). The extensive information about the mother-child dyads, the richly phenotyped data, a higher than average incidence of child disability (Sheridan et al. 2013), and a large sample size, make $\mathrm{BiB}$ an ideal platform for examining caregiver healthcare use.

Our primary objective was to investigate differences in the frequency of healthcare use for physical and psychological ill health in UK mothers of disabled 
children compared with other mothers during the preschool period. Our research questions were: 1) do mothers of young disabled children visit the doctor as often as other mothers; 2) are there differences in visit frequency for psychological or physical ill health, and 3) how is visiting the doctor influenced by prenatal symptoms and socioeconomic status?

\section{Methods}

The Strobe guidelines for reporting cohort studies were used (von Elm et al. 2008).

\section{Study Sample}

The study sample were paired mothers and children from the $\mathrm{BiB}$ cohort who met the inclusion criteria: 1) electronic primary care records available for the full study period (from 12 months before and five years after the index child's birth); 2) a BiB baseline questionnaire; 3) linked primary care records available for the index child from ages $0-5 ; 4$ ) children who survived beyond the age of five; 5) one child per mother. If a mother had more than one child, the first born was selected. Only mothers were included as they are typically the primary caregiver.

\section{Exclusions}

We excluded 2726 mothers (21.9\%) and 4049 pregnancies $(29.4 \%)$ from the sample for not meeting the inclusion criteria (Fig. 1).

\section{Case Ascertainment}

All primary care practices in Bradford use the SystmOne electronic record system (The Phoenix Partnership (TPP) 2019). The lists of clinical codes for case ascertainment used the hierarchically organised clinical code language Clinical Terms Version 3 (Read codes). To ascertain whether mothers in the BiB cohort were caregiving for preschool children with disabilities, the children's primary care records were searched for Read codes for conditions: 1) classified as developmental disabilities and typically associated with substantial long term disability, 2) which can be identified during the preschool period, and 3) which have a prevalence $\geq 1$ in 10,000 (Horridge et al. 2016). We used the specific conditions of autism spectrum disorders (ASD), Down syndrome, cerebral palsy, Fragile X syndrome and moderateprofound learning disability.

To mitigate the risk of too small a caregiver group to perform the planned analyses, Read codes for developmental delay, developmental disorders (generalised or relating to specific developmental characteristics), mild or unknown severity learning disability, and generic disability (for example on the learning disability register and disability not otherwise specified) were included in the case ascertainment strategy. 


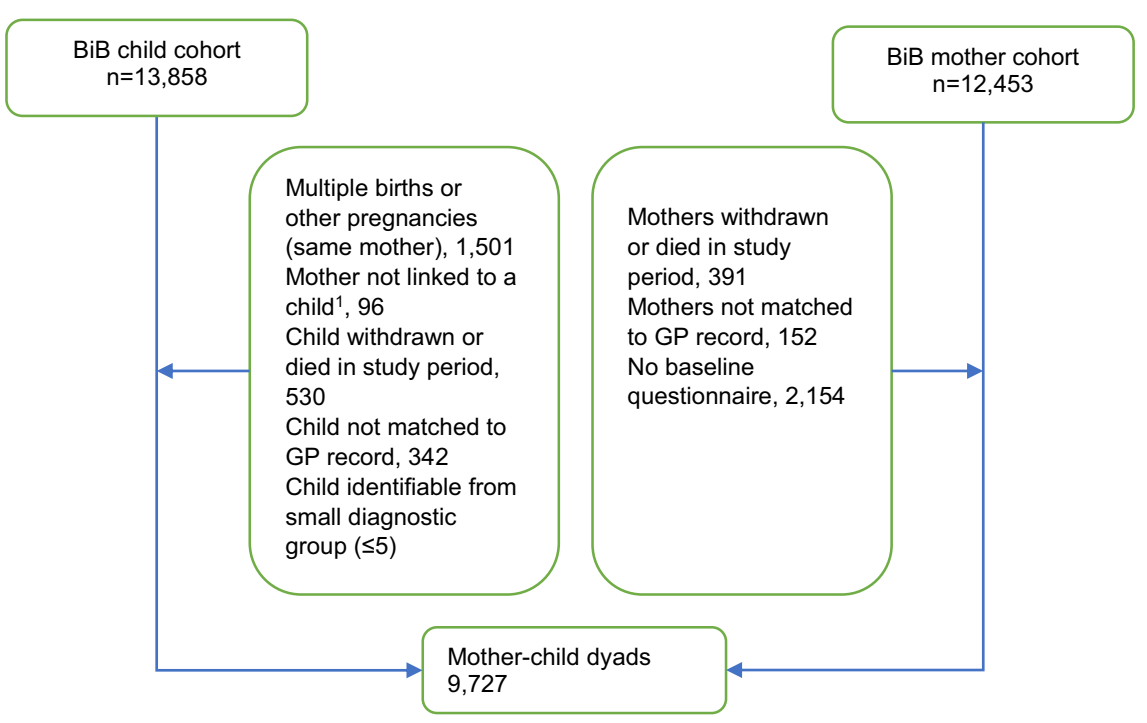

\section{Exclusions not mutually exclusive.}

${ }^{1}$ No linked child if the mother moved away from Bradford between being recruited to the study and giving birth

Fig. 1 Flow diagram of the eligible study sample from the BiB cohort

We aimed for a sample size of around 100 caregivers and 100 other mothers, which was identified as the minimum required to detect a statistically significant $(p<0.05)$ association between caregiving for young disabled children and clinical levels of psychological distress in another study (Scott et al. 1997).

\section{Maternal Symptoms of III Health}

The primary care records of the mothers were searched for six symptoms of ill health: stress, common mental disorders, fatigue, sleep problems, headaches/ migraines, and musculoskeletal (MSK) pain. These symptoms might reasonably be expected to occur in women of child-bearing age and be identified within a 12 month timeframe, have been found to have a higher prevalence in mothers of disabled children, and can be caused or exacerbated by stress (Lee et al. 2017; Miodrag et al. 2015) (Online Resource 1).

For each symptom, Read code lists for signs, symptoms and disorders that identify the symptoms via a single code were drawn up. For common mental disorders we adapted an existing list developed for use in the BiB cohort (Prady et al. 2016). The lists were combined to produce three symptom groups: psychological distress (stress and common mental disorders), exhaustion (fatigue and sleep problems) and head and musculoskeletal (MSK) pain. We combined them because a low number of visits to the doctor was expected for each symptom as women of child-bearing age are a generally healthy group. 


\section{Analysis}

We assessed the relationship between caregiver status and healthcare use for the three different symptom groups, adjusting for prenatal healthcare use and sociodemographic factors. Healthcare use is preceded by health-seeking behaviour, whereby the individual recognises a health problem and decides to do something to alleviate the clinical symptom (Cornally and McCarthy 2011). Therefore, to fully investigate how frequently caregivers visit the doctor compared with other mothers, the rate of healthcare-seeking behaviour ( $\geq 0$ visits) was modelled as well as the rate of healthcare use ( $\geq 1$ visit i.e. healthcare use by only the mothers who demonstrated healthcare-seeking behaviour). We explored the relationship between caregiver status and the rate of consultation for the symptom group using a negative binomial/Poisson regression. The relationship between caregiver status and the likelihood of healthcare-seeking behaviour via primary care consultation was examined using a zero-inflated negative binomial/Poisson regression. Negative binomial regression was used when right-tailed skew was found in the consultation frequency variables due to most women in the study population not visiting the doctor during the study period and most of those that did only visiting once. We determined the best model for the data using descriptive statistics, assessments of equidispersion and goodness of fit (the model with the lowest Akaike and Bayesian Information Criterion was the best fit) (Greene 1994).

A zero-inflated negative binomial regression model was used as some of the mothers who did not visit the doctor would also be experiencing symptoms. The two part model: a) estimated the probability (odds ratio) of the mothers not visiting the doctor because they did not have symptoms (known as certain zeros), and then $b$ ) estimated the relative rate ratio based on some of the excess zeros (no visits) not being certain zeros (the likelihood that more mothers had the symptom than visited the doctor about it) (Hilbe 2012). We included covariates with a known or theorised relationship to the outcomes and were mindful not to overspecify the model (Schisterman et al. 2009). We included symptom group consultation frequency in the year before the child's birth (prenatal covariate), socioeconomic status indicators (education, ethnicity, cohabitation status, subjective financial status) all collected during pregnancy, and mother's age at the child's birth.

Two initial analyses were performed: 1) a bivariate analysis to investigate whether any covariates had an association (alpha $<0.05$ ) with caregiver status, something which might confound the subsequent analyses; 2) multivariate logistic regression to establish the prevalence of the symptom groups, adjusted for the covariates.

The statistical analyses were performed in Stata 15 (StataCorp LLC 2018), with an alpha of 0.05 where $p<0.05$ indicated evidence of, and $p \leq 0.1$ indicated a tendency, for a relationship (Gigerenzer et al. 2004). Ninety-five percent confidence intervals were produced around all estimates. A complete case analysis of the data was performed without missing values being imputed. 
Individual participants were dropped from the dataset when there were fewer than five children with a specific disability to avoid the possibility of compromising anonymity. Categories within a variable were collapsed if this would raise the count above five without obscuring the categories in which the caregivers and other mothers were theorised to vary.

\section{Results}

The analytic sample included 477 caregivers of preschool disabled children and 7250 other mothers, $78.1 \%(9727 / 12,453)$ of the recruited mothers in the $\mathrm{BiB}$ cohort. The caregiver group was comprised of 83 mothers of children with disabling conditions: ASD $(n=47)$, Down syndrome $(n=24)$ and cerebral palsy $(n=12)$ and 394 mothers of children with indicators of disability: developmental delay $(n=371)$; developmental disorders $(n=28)$; unspecified disability $(n=9)$ and mild or unknown severity learning disability $(n=3)$. Fewer than five children received diagnoses of Fragile $\mathrm{X}$ syndrome or moderate-profound learning disability and were excluded from the sample.

Table 1 shows the sociodemographic and health characteristics of the sample by caregiver status. The amount of missing data was low $(\leq 0.6 \%)$. No statistically significant relationships between the covariates and caregiver status were observed, indicating confounding was unlikely. There was evidence of an association between caregiving for children with developmental disabilities and increased postnatal prevalence of psychological distress (odds ratio (OR) 1.24, 95\% confidence interval (CI) $1.01,1.53$ ) and exhaustion (OR 1.42; CI 1.12, 1.80) and possibly head and MSK pain (OR 1.18, CI 0.97, 1.43) after adjusting for prenatal ill health and socioeconomic status (Online Resource 2).

\section{Consultation Frequency}

The results of the multivariate analyses of the relationship between caregiver status and: 1) healthcare use ( $\geq 1$ primary care visits) for each symptom group, and 2 ) healthcare-seeking behaviour ( $\geq 0$ primary care visits) are shown in Tables 2 and 3 respectively.

There was a very small (1\%) increase in the rate of postnatal healthcare use for psychological distress associated with caregiving (relative rate ratio (RRR) 1.01; CI $0.89,1.13$ ) (Table 2). There was also a suggestion that, compared with other mothers, caregivers were more likely to have Read codes for psychological distress recorded but sought primary healthcare less often (OR 0.64; 0.40, 1.02) (Table 3). There was no evidence that caregiving influences whether, or how frequently, mothers consult the doctor after the child's birth for head and MSK pain or exhaustion (Tables 2 and 3). 
Table 1 Sociodemographic and health characteristics of the mothers by caregiver status

\begin{tabular}{|c|c|c|c|}
\hline Variable & Other mothers $(n=9250)$ & Caregivers $(n=477)$ & Total $(n=9727)$ \\
\hline $\begin{array}{l}\text { Mother's age (in years), mean (s.d.), } \\
\text { range }\end{array}$ & $27.5(5.6), 15-44$ & $27.6(6.0), 15-49$ & $27.5(5.6), 15-49$ \\
\hline \multicolumn{4}{|l|}{ Parity, n column $(\%)^{\mathrm{a}}$} \\
\hline First child & $9249(100)$ & $435(91.2)$ & 9684 (99.6) \\
\hline$\geq 2$ children & $1^{\mathrm{a}}(0.0)$ & $42(8.8)$ & $43(0.4)$ \\
\hline Missing & 0 & 0 & 0 \\
\hline \multicolumn{4}{|l|}{ Cohabitation status, $\mathrm{n}$ column $(\%)$} \\
\hline Living with partner & $7642(82.6)$ & $401(83.9)$ & $8042(82.7)$ \\
\hline Not living with partner & $1589(17.2)$ & $77(16.1)$ & $1666(17.13)$ \\
\hline Missing & $19(0.2)$ & 0 & $19(0.2)$ \\
\hline \multicolumn{4}{|l|}{ Ethnicity, $\mathrm{n}$ column $(\%)$} \\
\hline White British & $3729(40.3)$ & $193(40.6)$ & $3922(40.3)$ \\
\hline Other & $1462(15.8)$ & $56(11.7)$ & $1518(15.6)$ \\
\hline Pakistani & 4040 (43.7) & $228(47.8)$ & 4268 (43.9) \\
\hline Missing & $19(0.2)$ & 0 & $19(0.2)$ \\
\hline \multicolumn{4}{|l|}{ Education, n column (\%) } \\
\hline $\begin{array}{l}\text { Higher education (beyond age } \\
\text { 16) }\end{array}$ & $4440(48.0)$ & $230(48.2)$ & $4670(48.0)$ \\
\hline $\begin{array}{l}\text { Compulsory education (to age } \\
16 \text { ) }\end{array}$ & $4784(51.7)$ & $246(51.6)$ & $5030(51.7)$ \\
\hline Missing & $26(0.3)$ & $1(0.2)$ & $27(0.3)$ \\
\hline \multicolumn{4}{|l|}{ Index of Multiple Deprivation } \\
\hline 1 (highest SES) & $164(1.8)$ & $6(1.3)$ & $170(1.8)$ \\
\hline 2 & $320(3.5)$ & $14(2.9)$ & $334(3.4)$ \\
\hline 3 & $1117(12.1)$ & $44(9.2)$ & $1161(11.9)$ \\
\hline 4 & $1702(18.4)$ & $86(18.0)$ & $1788(18.4)$ \\
\hline 5 (lowest SES) & $5944(64.3)$ & $327(68.6)$ & $6271(64.5)$ \\
\hline Missing & $3(0.0)$ & 0 & $3(0.0)$ \\
\hline \multicolumn{4}{|l|}{ Subjective financial status, $\mathrm{n}$ column (\%) } \\
\hline Living comfortably & $2480(26.8)$ & $107(22.4)$ & $2587(26.6)$ \\
\hline Doing alright & $3833(41.4)$ & $210(44.0)$ & $4043(41.6)$ \\
\hline Just about getting by & $2174(23.5)$ & $115(24.1)$ & $2289(23.5)$ \\
\hline Quite difficult & $536(5.8)$ & $27(5.7)$ & $563(5.8)$ \\
\hline Very difficult & $176(1.9)$ & $12(2.5)$ & $188(1.9)$ \\
\hline Missing $^{\mathrm{b}}$ & $51(0.6)$ & $6(1.3)$ & $57(0.6)$ \\
\hline \multicolumn{4}{|c|}{ Symptom groups detected before the child's birth } \\
\hline Psychological distress & $636(6.9)$ & $37(7.8)$ & $673(6.9)$ \\
\hline Head and MSK pain & $1429(15.5)$ & $72(15.1)$ & $1501(15.4)$ \\
\hline Exhaustion & $275(3.0)$ & $12(2.5)$ & $287(3.0)$ \\
\hline \multicolumn{4}{|c|}{ Number of symptom groups detected before the child's birth, $\mathrm{n}$ column $(\%)^{\mathrm{c}}$} \\
\hline 0 & $7585(82.0)$ & 394 (82.6) & $7979(82.0)$ \\
\hline$\geq 1$ & 1665 (18.0) & 83 (17.4) & $1748(18.0)$ \\
\hline$\geq 2$ & $194(2.1)$ & $15(3.1)$ & $210(2.2)$ \\
\hline
\end{tabular}


Table 1 (continued)

\begin{tabular}{lccc}
\hline Variable & Other mothers $(n=9250)$ & Caregivers $(n=477)$ & Total $(n=9727)$ \\
\hline$\geq 3$ & $13(0.1)$ & 0 & $13(0.1)$ \\
Symptom group detected after the child's birth & & \\
$\quad$ Psychological distress & $2789(30.2)$ & $165(34.6)$ & $2954(30.4)$ \\
Head and MSK pain & $3612(39.1)$ & $207(43.4)$ & $3819(39.3)$ \\
Exhaustion & $1334(14.4)$ & $92(19.3)$ & $1425(14.7)$ \\
Number of symptom groups detected after the child's birth ${ }^{\mathrm{c}}$ & & \\
0 & $4431(47.9)$ & $190(39.8)$ & $8026(82.5)$ \\
$\geq 1$ & $4819(52.1)$ & $287(60.2)$ & $5106(52.5)$ \\
$\geq 2$ & $1602(17.33)$ & $98(20.55)$ & $1701(17.5)$ \\
$\geq 3$ & $312(3.4)$ & $25(5.24)$ & $337(3.5)$ \\
Symptom groups detected both before and after the child's birth & & \\
Psychological distress & $420(4.5)$ & $24(5.0)$ & $844(4.6)$ \\
Head and MSK pain & $858(9.3)$ & $41(8.6)$ & $94(1.0)$ \\
Exhaustion & $86(0.9)$ & $8(1.7)$ &
\end{tabular}

Consultation frequency (including zero visits) before the child's birth, mean (s.d), range
Psychological distress
$0.1(0.6), 0-17$
$0.1(0.6), 0-6$
$0.1(0.6), 0-17$
Head and MSK pain
0.2 (0.6), 0-7
$0.2(0.5), 0-3$
0.2 (0.6), 0-7
Exhaustion
0.03 (0.2), 0-4
$0.03(0.2), 0-2$
$0.03(0.2), 0-4$

Consultation frequency (including zero visits) after the child's birth, mean (s.d), range
Psychological distress
0.9 (2.3), $0-56$
$1.1(2.0), 0-11$
0.9 (2.3), 0-56
Head and MSK pain
0.9 (1.7), $0-25$
1.0 (1.7), 0-11
0.9 (1.7), 0-25
Exhaustion
0.2 (0.5), 0-6
0.3 (0.6), 0-5
0.2 (0.5), 0-6

Consultation frequency (only mothers who visited) before the child's birth, mean (s.d) range
Psychological distress
1.8 (1.5), $1-17$
1.8 (1.4), $1-6$
$1.8(1.5), 1-17$
Head and MSK pain
1.3 (0.7), 1-7
1.3 (0.5), 1-3
1.3 (0.7), 1-7
Exhaustion
1.1 (0.4), 1-4
1.2 (0.4), 1-2
$1.1(0.4), 1-4$

Consultation frequency (only mothers who visited) for the five years after the child's birth, mean (s.d) range

$\begin{array}{llll}\text { Psychological distress } & 3.1(3.3), 1-56 & 3.1(2.4), 1-11 & 3.1(3.3), 1-56 \\ \text { Head and MSK pain } & 2.2(2.1), 1-25 & 2.3(1.9), 1-11 & 2.2(2.1), 1-25 \\ \text { Exhaustion } & 1.3(0.7), 1-6 & 1.4(0.7), 1-5 & 1.3(0.7), 1-6\end{array}$

${ }^{a}$ Although there is a cell count of less than 5 for this variable, the data are presented as the individual was not considered at risk of re-identification from the summary data presented

${ }^{\mathrm{b}}$ Missing includes does not wish to answer

${ }^{\mathrm{c}}$ Across the symptom groups: psychological distress, head and MSK pain and/or exhaustion

\section{Covariate Relationships}

Prenatal healthcare-seeking behaviour was associated with a higher postnatal rate of healthcare use (visiting more than once) and healthcare-seeking behaviour (visiting at all when experiencing symptoms) (Tables 2 and 3). There was evidence that socioeconomic disadvantage was associated with both increased healthcare use and decreased healthcare-seeking behaviour (Tables 2 and 3). However, the magnitude 


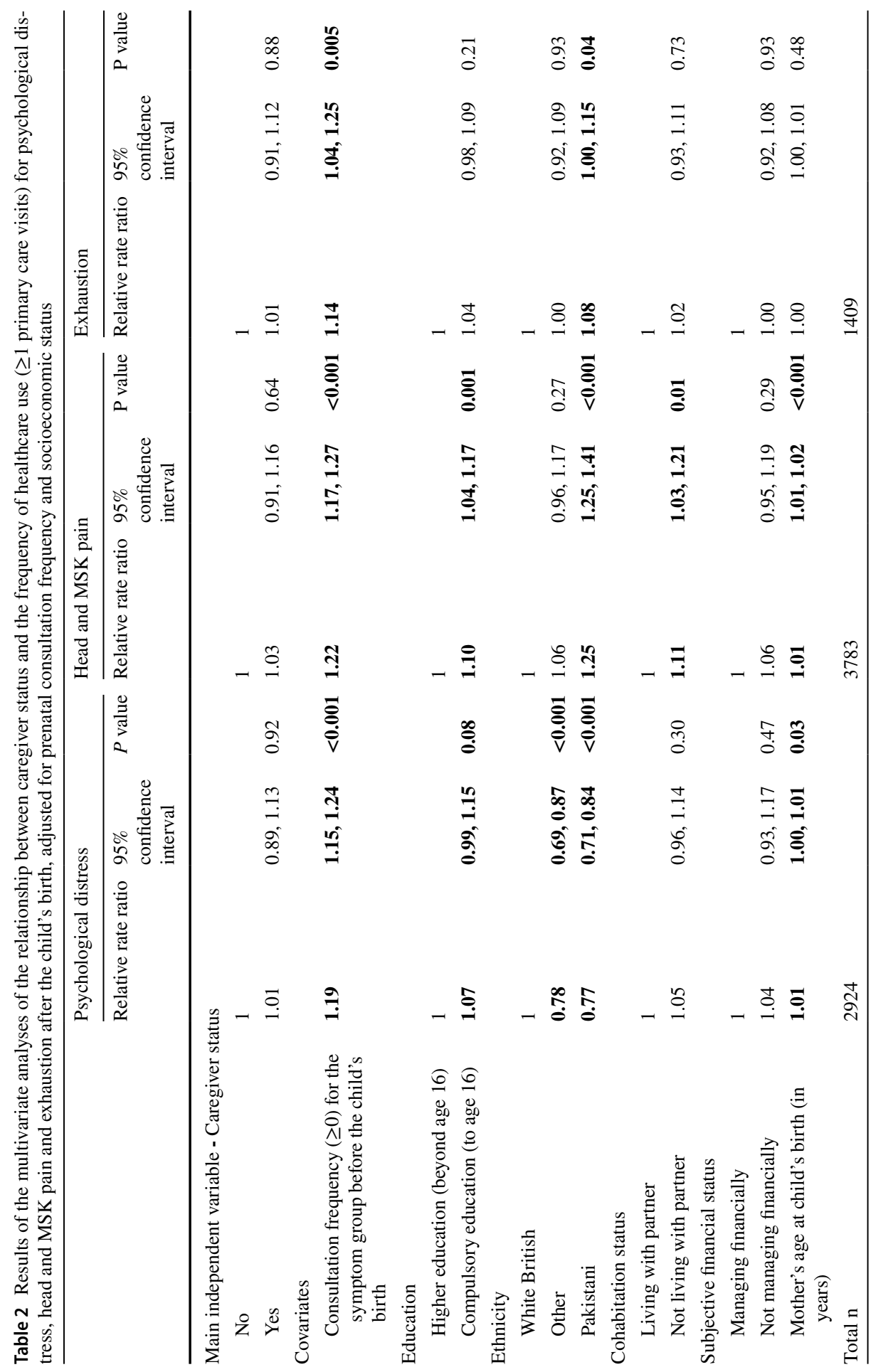




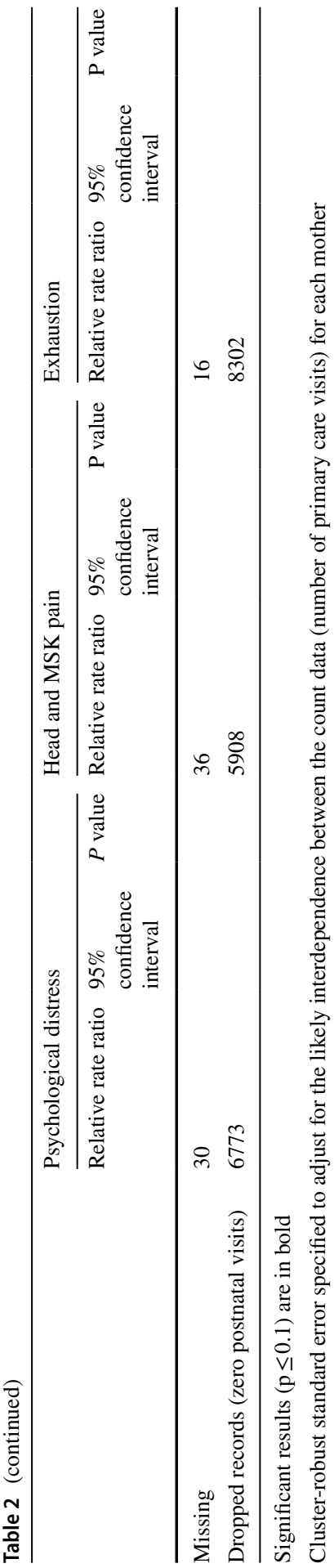




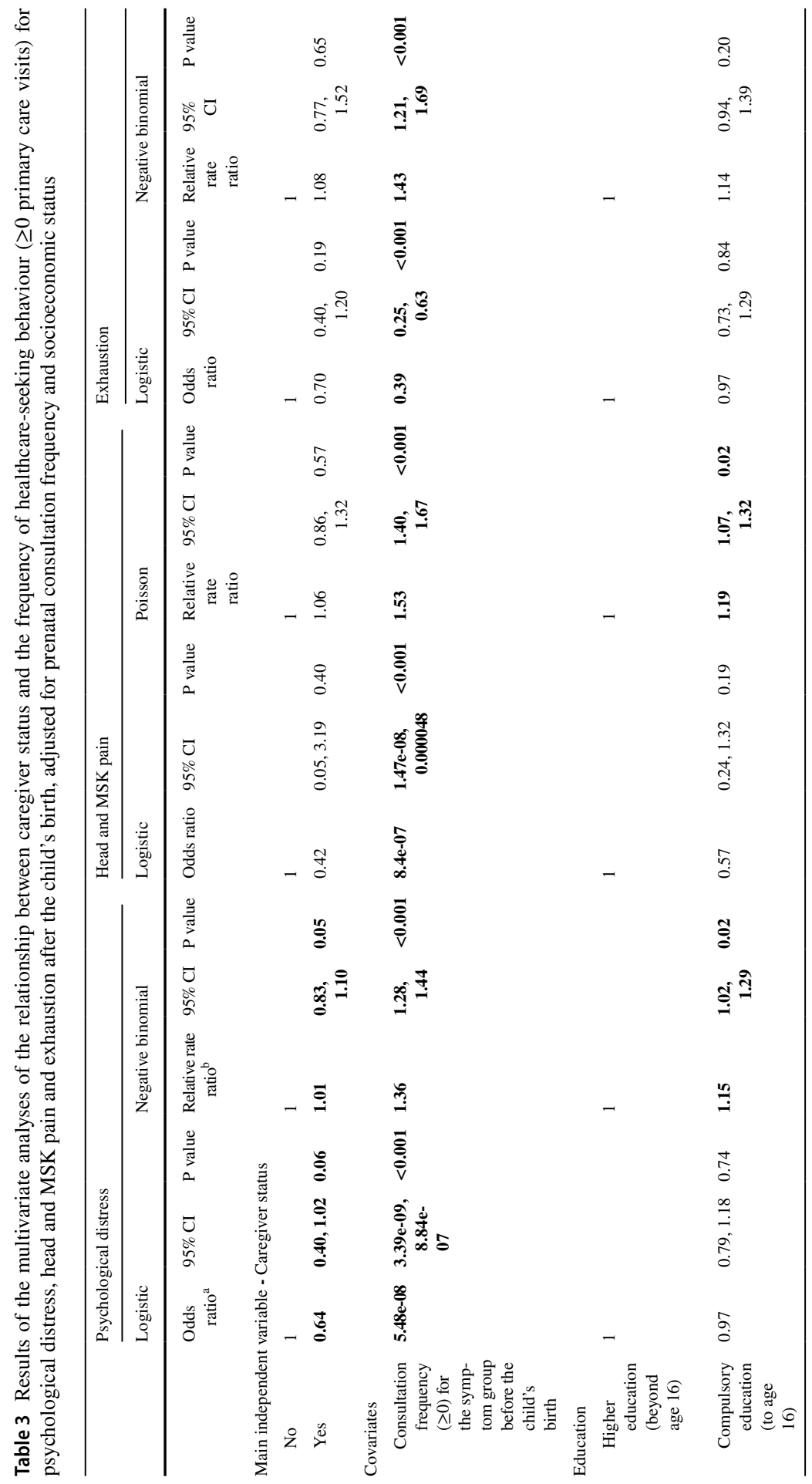




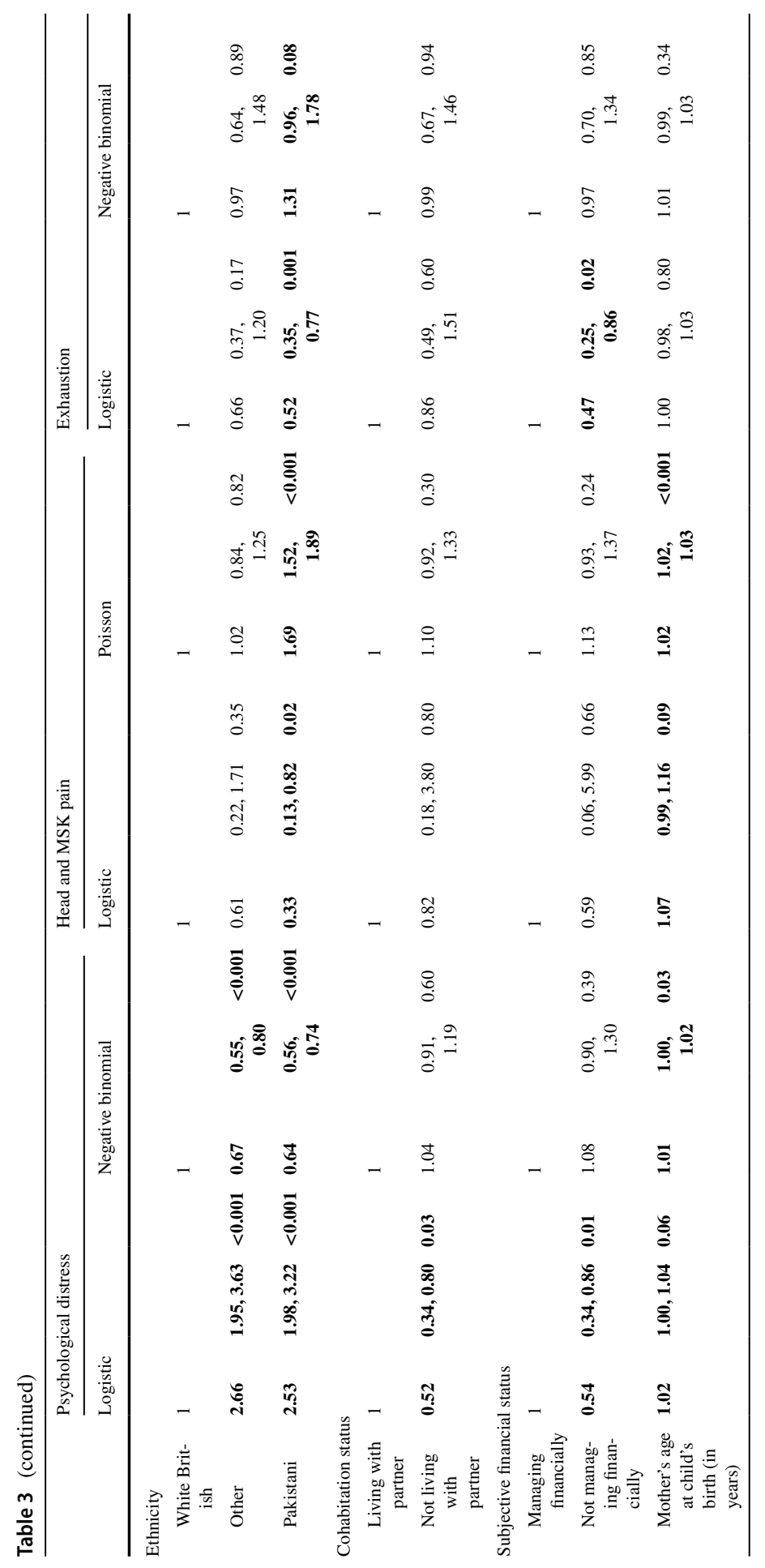




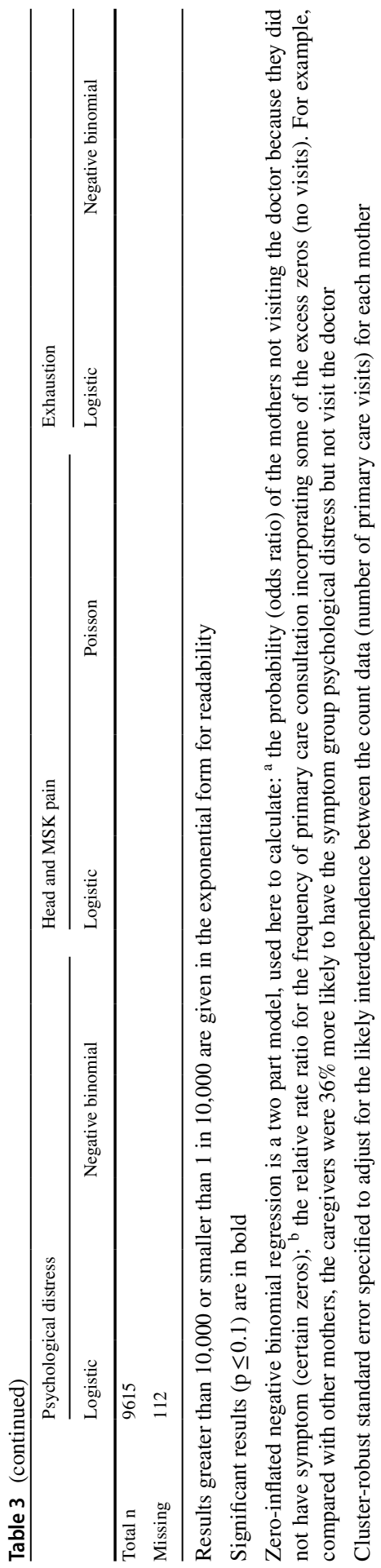


and significance of the relationships of the specific indicators of socioeconomic status varied within and between the symptom groups. A notable variation was the decreased consultation frequency for psychological distress in Pakistani compared with white British mothers, but increased consultation frequency for the other symptom groups (Table 2).

\section{Discussion}

This is the first study to compare healthcare use (and also prevalence estimates for ill health) in caregivers of preschool aged children with and without developmental disabilities in the UK, and one of very few to adjust for prenatal ill health and socioeconomic status. We found evidence of an association between caregiving and a higher prevalence of ill health for all three symptom groups. This is consistent with the published literature (Lee et al. 2017; Miodrag et al. 2015; Tong et al. 2003). We also found that despite having a higher prevalence of the symptom groups, caregivers did not seek more healthcare, and may have even sought less healthcare for psychological distress. Thus, caregiver burden may have hindered healthcare-seeking behaviour for some, leading to an increased risk of the under-detection in caregivers compared with other mothers.

Few studies have examined the relationship between caregiving for a disabled child and caregiver healthcare use. We are only aware of one other study with results showing a similar relationship between caregiving and healthcare use. Willet et al. (2018) in Australia found that caregiver distress (clinical need) was the greatest predictor of healthcare-seeking behaviour, but there were barriers to healthcare use affecting caregivers' decisions on whether to visit the doctor. Lower healthcare use has also been reported in family caregivers, including caregivers of children, compared with non-caregivers in the UK (Arksey and Hirst 2005).

Other studies have found a positive association between caregiving and healthcare use (primary, secondary, emergency and psychological service visits and medication use). This increased use has been attributed to caregiver psychological distress, high child healthcare use, child behavioural problems, and the specific diagnoses of ASD and learning disability (Thurston et al. 2011; Brehaut et al. 2019; Le et al. 2016; Fairthorne et al. 2016).

The difference in results could be due to a number of factors. Other studies rarely adjusted in their analysis for prenatal ill health, which has been shown to be associated with higher use postnatally. It might be that frequent contact caregivers have with primary care services during the preschool period due to routine appointments with primary care doctors and health visitors is important (Miller et al. 2006). Alternatively, it could be due to the other studies reporting findings based in different healthcare systems.

\section{Influence of Other Factors on Health and Healthcare Use}

Consistent with the literature, all mothers in our study with previous healthcare use for a symptom had a higher frequency of postnatal healthcare use (da Silva et al. 2017). Thus, prenatal healthcare use may influence whether caregivers seek support 
for symptoms of ill health via primary care services. Therefore, caregivers who had not previously experienced psychological distress or who had experienced symptoms but had not previously sought treatment in primary care, may be at greater risk of undetected and, therefore, untreated and persistent symptoms than mothers who had sought help prenatally.

Our sample came from a largely bi-ethnic (white British and Pakistani) socioeconomically disadvantaged population. We adjusted for socioeconomic status in the analyses as disadvantage is known to influence health and healthcare use in the BiB cohort and more widely (Kelly et al. 2017), though unlike some studies caregivers in our sample were not more socioeconomically disadvantaged than the other mothers (Masefield et al. 2020). Disadvantage (via indicators of education, subjective financial status, cohabitation status) was associated with both increased healthcare use and decreased primary healthcare-seeking behaviour; thus increasing the risk of the under-detection of each symptom group in disadvantaged mothers so compounding disparities.

$\mathrm{BiB}$ mothers with ill health living in socioeconomically deprived areas and of Pakistani ethnicity have been found to visit their doctor less often than more affluent, white British mothers (Kelly et al. 2017). Our findings suggest the relationship between socioeconomic status and primary healthcare use may vary by symptom, and that there can be both a high consultation rate and underuse within the same population.

There was also notable variation in the relationship of ethnicity to the outcomes by symptom group. Despite Pakistani ethnicity being associated with socioeconomic disadvantage (Wright et al. 2013), Pakistani mothers had a lower consultation rate for psychological distress than white British mothers. This may reflect variation in clinical need by ethnicity (e.g. a lower prevalence of psychological distress), or differences in how psychological versus physical conditions and the appropriateness of healthcare use are considered within different cultures. Postnatal psychological distress may be twice as likely to be missed in minority ethnic than white British mothers in the BiB cohort (Prady et al. 2016). Thus, the raised consultation rate for head and MSK pain and exhaustion for Pakistani mothers in our study may reflect repeat visits due to the initial misidentification of psychological distress. If so, the true consultation prevalence of psychological distress may be higher and the prevalence of exhaustion and pain unrelated to psychological distress lower.

\section{Strengths and Limitations}

We have shown how routinely collected primary healthcare data can be used to investigate caregiver healthcare use. Our study provides new understanding of the relationships between health, healthcare use and caregiving during the preschool period, and highlights correlates of ill health and low healthcare use in the UK.

We developed a practical strategy for identifying preschool children with developmental disabilities via primary care records. This resulted in a group with heterogenous disability characteristics and with unknown disability severity and behavioural problems. These characteristics may vary in different population groups, limiting the generalisability of the results. 
We underestimate the true prevalence of each symptom group as both prevalence and consultation frequency estimates are predicated on mothers with ill health visiting the doctor, and the identification and recording of symptoms using appropriate Read codes and their detection via our symptom group identification strategy. The extent of the under-detection of ill health in the sample may also vary by symptom and possibly between the caregiver and other mother groups. For example, most people purchase over-the-counter medication as the primary strategy for pain management (Latinovic et al. 2006); whilst psychological distress is under-recorded in primary care records for a variety of reasons (National Institute for Health and Care Excellence 2011). The exclusion of drug codes for most of the symptoms will also have resulted in an unknown amount of symptom group underestimation. However, primary care records are a good indicator of clinical need as people in the UK, in the main, visit the doctor when their symptoms are adversely affecting their daily lives, and thus are clinically significant (Martin-Merino et al. 2010). Our findings may therefore indicate clinical significance as perceived by the mothers that visited their doctor.

Symptom groups were used because of clinical similarities and to produce large enough outcome groups to perform the planned analyses. However, this meant an increase in clinical heterogeneity within the symptom groups used.

To avoid model overspecification and because of their unavailability for the $\mathrm{BiB}$ cohort, we excluded some covariates with a known relationship to caregiver ill health, for example caregiver social support and personality, family size and child behavioural problems (Estes et al. 2013; Fonseca et al. 2014; Marquis et al. 2019). Some of the estimates of effect observed, therefore, may have been affected by unmeasured factors.

Our findings indicate a possible relationship between caregiving and healthcare use for a clinically heterogeneous group of preschool children with many unknown disability characteristics such as behavioural problems, severity, or additional health problems. Our estimates might therefore not be replicated in more tightly defined groups of caregivers and other mothers. Although our findings are consistent with some other studies, generalisability might be limited by the unique ethnic and social composition of the sample and, perhaps, combination of disability diagnoses. There may also be differences in healthcare use due to differences in healthcare systems (e.g. national tax-based, insurance-based, private and mixed models). However, caregiver burden is not unique to the caregiver group in our study population. The mechanism by which caregivers of disabled preschool children experience greater ill health and which may be under-detected due to low primary healthcare-seeking behaviour is generalisable to other caregiver groups.

It is likely that the greater prevalence of ill health and lower consultation frequency for psychological distress in the caregivers is due to the burden of caregiving for a disabled child, and we used a prospective design and investigated confounding, yet we cannot infer causality from this observational study.

\section{Recommendations for Future Research}

Further research on barriers (and enabling factors) to caregivers' healthcare use and the extent to which they influence caregiver healthcare use would aid understanding 
of potential under-detection. Comparisons between routinely collected health data (i.e. consultation prevalence) and assessment of clinical need using standardised measures could highlight the clinical extent of any under-detection.

Further research is needed to understand geographical variation and variation between reported and recorded ill-health and healthcare-seeking by parent-caregivers, such as differences in the support received by caregivers via primary care services, sociodemographic differences between samples and the extent to which caregivers are using alternatives to primary care (e.g. third or private sector counselling, emergency services or religious/folk based practitioners and remedies) (Rhodes et al. 2008).

Research should also focus on how to increase detection and lower barriers. This might include appraisal of the extent to which healthcare services in contact with caregivers assess caregiver burden and the robustness, including the sensitivity to ethnic differences, of that assessment. The extent of family-centred support, including information and signposting about local and national benefits and support is also worthy of study. Improvements in these areas could reduce the risk of growing socioeconomic and health inequalities between caregivers and other mothers and between advantaged and disadvantaged caregivers.

\section{Conclusion}

This study has shown that caregiving for young disabled children is associated with an increased prevalence of some symptoms, not reflected in increased healthcare use. If caregiver burden and the risk of under-detecting (and thus under treating) caregiver ill health is not addressed during the preschool period, health inequalities between caregivers and other mothers and their families may persist and grow.

Abbreviations ASD: Autism spectrum disorders; BiB: Born in Bradford; OR: Odds ratio; RRR: Relative rate ratio; $\mathrm{CI}$ : Confidence interval

Supplementary Information The online version contains supplementary material available at https://doi. org/10.1007/s10882-021-09789-7.

Acknowledgements Born in Bradford is only possible because of the enthusiasm and commitment of the Children and Parents in $\mathrm{BiB}$. We are grateful to all the participants, health professionals and researchers who have made Born in Bradford happen. We gratefully acknowledge the contribution of TPP and the TPP ResearchOne team in completing study participant matching to GP primary care records and in providing ongoing informatics support. Thank you to Prof Lorna Fraser, Dr. Bob Phillips, and Dr. Stella Yeung for their guidance in shaping the disability ascertainment strategy which informed this study.

Authors' Contribution All authors made substantial contributions to the conception and design of the work, analysis and interpretation of the data. SM drafted the manuscript and all other authors revised it critically for important intellectual content. All authors approved the manuscript and agreed to be accountable for all aspects of the work.

Funding Sarah Masefield was supported by a match funded studentship from the University of York and the Health e-Research Centre ref. PhD2016PP2. The remaining authors received no specific funding for this study. 
Data Availability Information about how to access Born in Bradford data is available at borninbradford. nhs.uk.

Code Availability The Read codes for the maternal symptoms are included in Online Resource 1 and will be submitted to the repository ClinicalCodes.org. The Read codes for the disability case ascertainment strategy are currently available upon request to the lead author and will be entered into the same repository prior to the publication of a further manuscript on the identification of disability in preschool aged children via primary care records.

\section{Declarations}

Ethics Approval The $\mathrm{BiB}$ data requested are sensitive personal data. $\mathrm{BiB}$ received ethical approval for the data collection from the Bradford Research Ethics Committee (Ref 07/H1302/112), which included specifying the requirement for informed consent to participate (for the mothers) and informed consent from legal guardians (for the children). The planned study received ethical scrutiny as part of the BiB data application, and adhered to the 1964 Helsinki declaration and subsequent amendments. No further ethical approval was required for the analysis of the data (decision confirmed in writing by the Chair of the University of York Health Sciences Department Research Governance Committee)as pseudonymised existing data were used and we complied with all standards and policies of the University of York's Data Management Policy (University of York Information Services, 2018).

Consent to Participate Consent obtained during recruitment to the Born in Bradford study, as outlined in the Ethics approval declaration.

Competing Interests The authors declare that they have no competing interests.

Open Access This article is licensed under a Creative Commons Attribution 4.0 International License, which permits use, sharing, adaptation, distribution and reproduction in any medium or format, as long as you give appropriate credit to the original author(s) and the source, provide a link to the Creative Commons licence, and indicate if changes were made. The images or other third party material in this article are included in the article's Creative Commons licence, unless indicated otherwise in a credit line to the material. If material is not included in the article's Creative Commons licence and your intended use is not permitted by statutory regulation or exceeds the permitted use, you will need to obtain permission directly from the copyright holder. To view a copy of this licence, visit http://creativecommons.org/licenses/by/4.0/.

\section{References}

Arksey, H., Hirst, M. (2005). Unpaid carers' access to and use of primary care services. York: University of York. http://eprints.whiterose.ac.uk/1625/1/spru_carersusePCS2.pdf. Accessed 15 Feb 2020.

Brehaut, J. C., Guevremont, A., Arim, R. G., Garner, R. E., Miller, A. R., McGrail, K. M., Brownell, M., Lach, L. M., Rosenbaum, P. L., \& Kohen, D. E. (2019). Changes in caregiver health in the years surrounding the birth of a child with health problems: Administrative data from British Columbia. Medical Care, 57(5), 369-376. https://doi.org/10.1097/mlr.0000000000001098.

Cans, C., De-la-Cruz, J., \& Mermet, M. (2008). Epidemiology of cerebral palsy. Paediatrics and Child Health, 18(9), 393-398.

Carlson, J. M., \& Miller, P. A. (2017). Family burden, child disability, and the adjustment of mothers caring for children with epilepsy: Role of social support and coping. Epilepsy \& Behavior, 68, 168173. https://doi.org/10.1016/j.yebeh.2017.01.013.

Chambers, H. G., \& Chambers, J. A. (2015). Effects of caregiving on the families of children and adults with disabilities. Physical Medicine \& Rehabilitation Clinics of North America, 26(1), 1-19. https:// doi.org/10.1016/j.pmr.2014.09.004.

Cornally, N., \& McCarthy, G. (2011). Help-seeking behaviour: A concept analysis. International Journal of Nursing Practice, 17(3), 280-288. https://doi.org/10.1111/j.1440-172X.2011.01936.x. 
da Silva, T., Mills, K., Brown, B. T., Herbert, R. D., Maher, C. G., \& Hancock, M. J. (2017). Risk of recurrence of low Back pain: A systematic review. The Journal of Orthopaedic and Sports Physical Therapy, 47(5), 305-313.

Estes, A., Olson, E., Sullivan, K., Greenson, J., Winter, J., Dawson, G., \& Munson, J. (2013). Parenting-related stress and psychological distress in mothers of toddlers with autism spectrum disorders. Brain \& Development, 35(2), 133-138. https://doi.org/10.1016/j.braindev.2012.10.004.

Fairthorne, J., de Klerk, N., \& Leonard, H. (2016). Brief report: Burden of care in mothers of children with autism spectrum disorder or intellectual disability. Journal of Autism and Developmental Disorders, 46(3), 1103-1109. https://doi.org/10.1007/s10803-015-2629-9.

Fonseca, A., Nazare, B., \& Canavarro, M. C. (2014). The role of satisfaction with social support in perceived burden and stress of parents of six-month-old infants with a congenital anomaly: Actor and partner effects. Journal of Child Health Care, 18(2), 178-191. https://doi.org/10.1177/1367493513485478.

Gigerenzer, G., Krauss, S., \& Vitouch, O. (2004). The null ritual: What you always wanted to know about significance testing but were afraid to ask. In D. Kaplan (Ed.), The sage handbook of quantitative methodology for the social sciences (pp. 391-408). Thousand Oaks: Sage Publications.

Greene, W. H. (1994). Accounting for excess zeros and sample selection in poisson and negative binomial regression models, Working papers. New York: New York University, Leonard N. Stern School of Business, Department of Economics.

Hilbe, J. M. (2012). Negative binomial regression. Cambridge: Cambridge University Press.

Horridge, K. A., Harvey, C., McGarry, K., Williams, J., Whitlingum, G., Busk, M., Fox, S., Baird, G., \& Spencer, A. (2016). Quantifying multifaceted needs captured at the point of care. Development of a disabilities terminology set and disabilities complexity scale. Developmental Medicine and Child Neurology, 58(6), 570-580. https://doi.org/10.1111/dmcn.13102.

Kelly, B., Mason, D., Petherick, E. S., Wright, J., Mohammed, M. A., \& Bates, C. (2017). Maternal health inequalities and GP provision: Investigating variation in consultation rates for women in the born in Bradford cohort. Public Health, 39(2), e48-e55. https://doi.org/10.1093/pubmed/fdw064.

Latinovic, R., Gulliford, M., \& Ridsdale, L. (2006). Headache and migraine in primary care: Consultation, prescription, and referral rates in a large population. Journal of Neurology, Neurosurgery, and Psychiatry, 77(3), 385-387. https://doi.org/10.1136/jnnp.2005.073221.

Le, H. N. D., Gold, L., Mensah, F. K., Cook, F., Bayer, J. K., \& Hiscock, H. (2016). Health service use and costs for infant behaviour problems and maternal stress. Journal of Paediatrics and Child Health, 52(4), 402-409. https://doi.org/10.1111/jpc.13095.

Lee, M., Park, C., Matthews, A. K., \& Hsieh, K. (2017). Differences in physical health, and health behaviors between family caregivers of children with and without disabilities. Disability and Health Journal, 10(4), 565-570. https://doi.org/10.1016/j.dhjo.2017.03.007.

Marquis, S., Hayes, M. V., \& McGrail, K. (2019). Factors affecting the health of caregivers of children who have an intellectual/developmental disability. Policy and Practice in Intellectual Disabilities, 16(3), 201-216. https://doi.org/10.1111/jppi.12283.

Martin-Merino, E., Ruigomez, A., Wallander, M. A., Johansson, S., \& Garcia-Rodriguez, L. A. (2010). Prevalence, incidence, morbidity and treatment patterns in a cohort of patients diagnosed with anxiety in UK primary care. Family Practice, 27(1), 9-16. https://doi.org/10.1093/fampra/cmp071.

Masefield, S. C., Prady, S. L., Sheldon, T. A., Small, N., Jarvis, S., \& Pickett, K. E. (2020). The caregiver health effects of caring for young children with developmental disabilities: A meta-analysis. Maternal and Child Health Journal, 24(5), 561-574. https://doi.org/10.1007/ s10995-020-02896-5.

Mayberry, L. S., \& Heflinger, C. A. (2013). How caregivers make meaning of child mental health problems: Toward understanding caregiver strain and help seeking. Journal of Family Social Work, 94(2), 105-113. https://doi.org/10.1606/1044-3894.4286.

Miller, R. L., Pallant, J. F., \& Negri, L. M. (2006). Anxiety and stress in the postpartum: Is there more to postnatal distress than depression? (OriginalPaper). BMC Psychiatry, 6(1), 12. https://doi.org/10. 1186/1471-244X-6-12.

Miodrag, N., Burke, M., Tanner-Smith, E., \& Hodapp, R. M. (2015). Adverse health in parents of children with disabilities and chronic health conditions: A meta-analysis using the parenting stress index's health sub-domain (meta-analysis). Journal of Intellectual Disability Research, 59(3), 257-271.

National Institute for Health and Care Excellence (2011). Clinical Guideline CG123. Common mental health problems: identification and pathways to care. London: NICE. https://www.nice.org.uk/guida nce/cg123/chapter/1-guidance. Accessed 05 June 2019. 
Olusanya, B. O., Davis, A. C., Wertlieb, D., Boo, N., Nair, M. K. C., Halpern, R., Kuper, H., Breinbauer, C., de Vries, P. J., Gladstone, M., Halfon, N., Kancherla, V., Mulaudzi, M. C., Kakooza-Mwesige, A., Ogbo, F. A., Olusanya, J. O., Williams, A. N., Wright, S. M., Manguerra, H., Smith, A., Echko, M., Ikeda, C., Liu, A., Millear, A., Ballesteros, K., Nichols, E., Erskine, H. E., Santomauro, D., Rankin, Z., Smith, M., Whiteford, H. A., Olsen, H. E., \& Kassebaum, N. J. (2018). Developmental disabilities among children younger than 5 years in 195 countries and territories, 1990-2016: A systematic analysis for the global burden of disease study 2016. The Lancet Global Health, 6(10), e1100-e1121. https://doi.org/10.1016/S2214-109X(18)30309-7.

Prady, S. L., Pickett, K. E., Petherick, E. S., Gilbody, S., Croudace, T., Mason, D., Sheldon, T. A., \& Wright, J. (2016). Evaluation of ethnic disparities in detection of depression and anxiety in primary care during the maternal period: Combined analysis of routine and cohort data. British Journal of Psychiatry, 208(5), 453-461. https://doi.org/10.1192/bjp.bp.114.158832.

Raina, P., O’Donnell, M., Schwellnus, H., Rosenbaum, P., King, G., Brehaut, J., Russell, D., Swinton, M., King, S., Wong, M., Walter, S. D., \& Wood, E. (2004). Caregiving process and caregiver burden: Conceptual models to guide research and practice. BMC Pediatrics, 4, 1. https://doi.org/10.1186/1471-2431-4-1.

Rhodes, P.J., Small, N., Ismail, H., Wright, J. P (2008). The use of biomedicine, complementary and alternative medicine, and ethnomedicine for the treatment of epilepsy among people of South Asian origin in the UK. BMC Complementary and Alternative Medicine, 8(7). https://doi.org/10.1186/ $1472-6882-8-7$

Schisterman, E. F., Cole, S. R., \& Platt, R. W. (2009). Overadjustment Bias and unnecessary adjustment in epidemiologic studies. Epidemiology, 20(4), 488-495. https://doi.org/10.1097/EDE.0b013e3181a819a1.

Scott, B. S., Atkinson, L., Minton, H. L., \& Bowman, T. (1997). Psychological distress of parents of infants with down syndrome. American Journal of Mental Retardation, 102(2), 161-171. https:// doi.org/10.1352/0895-8017(1997)1022.0.co;2.

Sheridan, E., Wright, J., Small, N., Corry, P. C., Oddie, S., Whibley, C., Petherick, E. S., Malik, T., Pawson, N., McKinney, P. A., \& Parslow, R. C. (2013). Risk factors for congenital anomaly in a multiethnic birth cohort: An analysis of the born in Bradford study. The Lancet. https://doi.org/10.1016/ S0140-6736(13)61132-0.

StataCorp LLC. (2018). 'Stata 15', Texas: StataCorp LLC. https://www.stata.com/why-use-stata/. Accessed 26 Sept 2019

The Phoenix Partnership (TPP). (2019). SystmOne. https://www.tpp-uk.com/products/systmone. Accessed 16 Sept 2019

Thurston, S., Paul, L., Loney, P., Ye, C., Wong, M., \& Browne, G. (2011). Associations and costs of parental symptoms of psychiatric distress in a multi-diagnosis group of children with special needs. Journal of Intellectual Disability Research, 55(3), 263-280. https://doi.org/10.1111/j.1365-2788.2010.01356.x.

Tong, H. C., Haig, A. J., Nelson, V. S., Yamakawa, K. S., Kandala, G., \& Shin, K. Y. (2003). Low back pain in adult female caregivers of children with physical disabilities. Archives of Pediatrics \& Adolescent Medicine, 157(11), 1128-1133. https://doi.org/10.1001/archpedi.157.11.1128.

Unicef and World Health Organization. (2012). Early childhood development and disability: A discussion paper. Geneva: WHO.

von Elm, E., Altman, D., Egger, M., Pocock, S., Gotzsche, P., \& Vandenbroucke, J. (2008). Strengthening the reporting of observational studies in epidemiology (STROBE) statement: Guidelines for reporting observational studies. Journal of Clinical Epidemiology, 61(4), 344-349.

Willet, M., Dorstyn, D., Due, C., \& Li, W. (2018). Applying Andersen's model to explain service use and quality of life among Australian caregivers of children with autism Spectrum disorder. Journal of Developmental and Physical Disabilities, 30(3), 1-16. https://doi.org/10.1007/s10882-018-9589-x.

Working Families and Unum (2018). '2018 Off Balance - Parents of disabled children and paid work'. London: Working Families. https://www.workingfamilies.org.uk/wp-content/uploads/2018/07/WF2018-Off-Balance-pages-FINAL.pdf. Accessed 14 Oct 2019.

Wright, J., Small, N., Raynor, P., Tuffnell, D., Bhopal, R., Cameron, N., Fairley, L., Lawlor, D. A., Parslow, R., Petherick, E. S., Pickett, K. E., Waiblinger, D., \& West, J. (2013). Cohort profile: The born in Bradford multi-ethnic family cohort study. International Journal of Epidemiology, 42(4), 978-991. https://doi.org/10.1093/ije/dys112.

Publisher's Note Springer Nature remains neutral with regard to jurisdictional claims in published maps and institutional affiliations. 


\section{Authors and Affiliations}

Sarah C. Masefield ${ }^{1,2} \odot$. Stephanie L. Prady ${ }^{1}\left({ }^{10} \cdot\right.$ Trevor A. Sheldon $^{3}(1) \cdot$ Neil Small ${ }^{4}$. Stuart Jarvis ${ }^{1}$ (I) $\cdot$ Kate E. Pickett ${ }^{1}$

1 Department of Health Sciences, University of York, York, UK

2 Present Address: Interdisciplinary Global Development Centre, University of York, York YO10 5DD, UK

3 School of Medicine and Dentistry, Queen Mary University of London, London, UK

4 Faculty of Health Studies, University of Bradford, Bradford, UK 